\title{
(4) \\ Fragility assessment of the connection used in small-scale residential steel house subjected to lateral wind loads
}

\author{
Viriyavudh Sim ${ }^{1}$, Jungkyu Choi ${ }^{2}$, WooYoung Jung ${ }^{3}{ }^{*}$ \\ 1, 2, 3 Department of Civil Engineering, Gangneung-Wonju National University, Gangneung, Gangwon, Korea
}

\author{
Index Terms \\ Lightweight Steel Frame \\ Monte Carlo Simulation \\ Wind Fragility
}

Received: 10 April 2017

Accepted: 3 May 2017

Published: 30 June 2017

\begin{abstract}
Typhoon disasters risk assessment is needed for small-scale residential houses with less than two stories or less than 500 square meters, since they accounted for about $55 \%$ of total buildings in Korea. Therefore, this study was focused on the evaluation of wind fragility for this small-scale lightweight steel frame structure when subjected to lateral wind loads. For this purpose, Monte Carlo Simulation technique was used to derive wind fragility based on random wind load parameters and experimental data of resistance capacity of the connection in this type of structure. Finally, the structural safety of a small-scale lightweight steel house was evaluated, and the fragility was derived. Results show that wind direction parallel to long dimension of structure was the most critical condition. Additionally, the median probability of failure occurs at a very high wind speed. Further research should focus on study with detail structural analysis to narrow down the uncertainty in this study.
\end{abstract}

\section{INTRODUCTION}

Small-scale residential houses with less than two stories or less than 500 square meters' have been excluded from safety evaluation of seismic design criteria in South Korea. Therefore, various risk assessments corresponding to structural systems and earthquake types are necessary to ensure the structural safety. However, in the case of South Korea where earthquakes hardly occur, it is more important to control the risk due to high wind disasters than those from earthquakes. Generally, risk assessment evaluation is needed to secure structural safety of the existing facilities. Due to the increment of natural hazards such as earthquake, typhoon, and flood, has lead the probabilistic risk assessment to be a key research area. Moreover, interest on safety of small scale steel frame structure has been on the rises in South Korea since this type of structure accounted for about $55 \%$ of total buildings. In general, steel frame structure composes of the upper steel frame and the base foun- dation. The superstructure connected to the foundation by connection that can have different arrangement. Thus, the type and configuration of the connection is the main factor to determine the strength and ductility of steel frames [1], [2].

Furthermore, [3] typhoon disaster in Korea in recent year has been on the rises. The risk due to typhoon cause devastating loss on economy and human life. Hence, the risk assessment for structure subject to wind load is required. In fact, Probabilistic Risk Assessment (PRA) has emerged as an increasingly popular analysis tool, especially in the last decade. For instance, [4] and [5] analyze fragility curve for wood frame structure subject to lateral wind loads by mean of Monte Carlo Simulation (MCS) method, which is a part of analytical fragility development. That method based on statistical wind load parameters determined by [6] by mean of Delphi questionnaire. Moreover, combined the statistical parameters with wind loads standard code [7] it can

\footnotetext{
${ }^{*}$ Corresponding author: WooYoung Jung

†Email: woojung@gwnu.ac.kr
} 
be applied to variety of structure types. For example, [8] and [9] used these parameters to determine failure probability of residential building and industrial building, respectively. Nevertheless, for small-scale steel structure in Korea, there are not many study for high wind disaster. Moreover, information of failure due to wind disasters were not well recorded for these types of structure [10] and [11].

Therefore, to contribute to this deficiency of risk assessment tool for these structures, the focused of this study was on lightweight steel frame structure subjected to lateral wind loads which focus on main wind force resistance system of the structure. The study fixated on the sum of lateral forces acting on the structure resulted from the wind pressure. By mean of MCS method, the random wind loads projected on the structure was simulated. This method can easily apply for structure with fewer historical recorded data of their performance in high wind disaster, which is highly suitable for Korea [12].

Additionally, with large numbers of random simulated wind pressure, the parameters of fragility curve of dif- ferent connection configuration could be determined. From this fragility, the assessment of connection performance could be discussed which can convolved with wind hazard curves to develop a risk assessment tool to estimate the expected loss due to the disaster [13].

\section{DESCRIPTION OF STRUCUTRE}

A small scale two stories steel frame structure was considered in this study (Fig. 1). The crucial focused for the assessment of this structure was the connection between steel column and base plate which include three different configurations as shown in Fig. 2 with the description in Table 1. Furthermore, each cases of connection were tested with loading on their strong axis and weak axis [14]. Backbone curves were derived from the cyclic loading [15]. The result of backbone curves was shown in Fig. 3. From this figure, we can determine their capacity which will be used in the following section as resistance capacity in the MCS method.
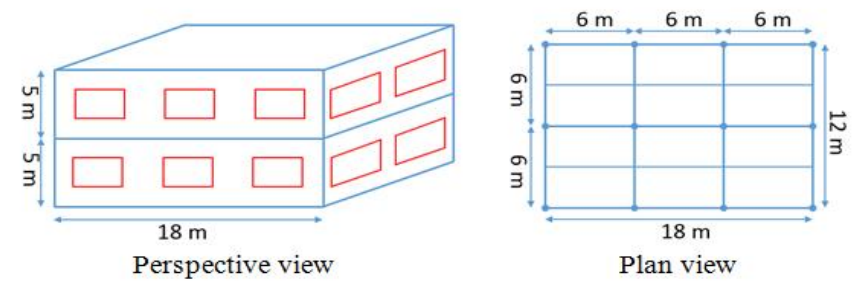

Fig. 1. Dimension of steel frame structure
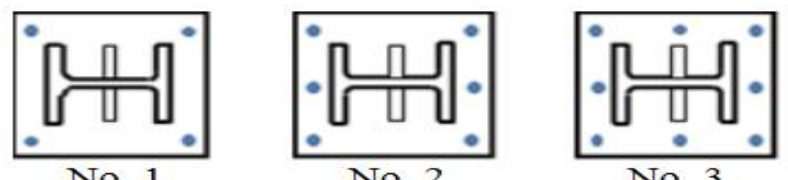

Fig. 2. Configuration of connection

TABLE 1

Description of connection configuration

\begin{tabular}{lllllll}
\hline \hline Specimen & \multicolumn{3}{c}{ Base Plate } & \multicolumn{2}{c}{ Anchor bolt } \\
\hline & Steel Grade Size (mm) & Thickness (mm) & No. Bolt (EA) & Embedded Depth (mm) & Hook Length (mm) \\
\hline No. 1 & SS400 & $450 \times 450$ & 25 & $6 / 4(1)$ & 650264 \\
No. 2 & SS400 & $450 \times 450$ & 25 & 6 & 650 & 264 \\
No. 3 & SS400 & $450 \times 450$ & 25 & 8 & 650 & 264 \\
\hline \hline
\end{tabular}

(1) Number of anchor bolts in case of strong axis: 6 and in case of weak axis: 4 


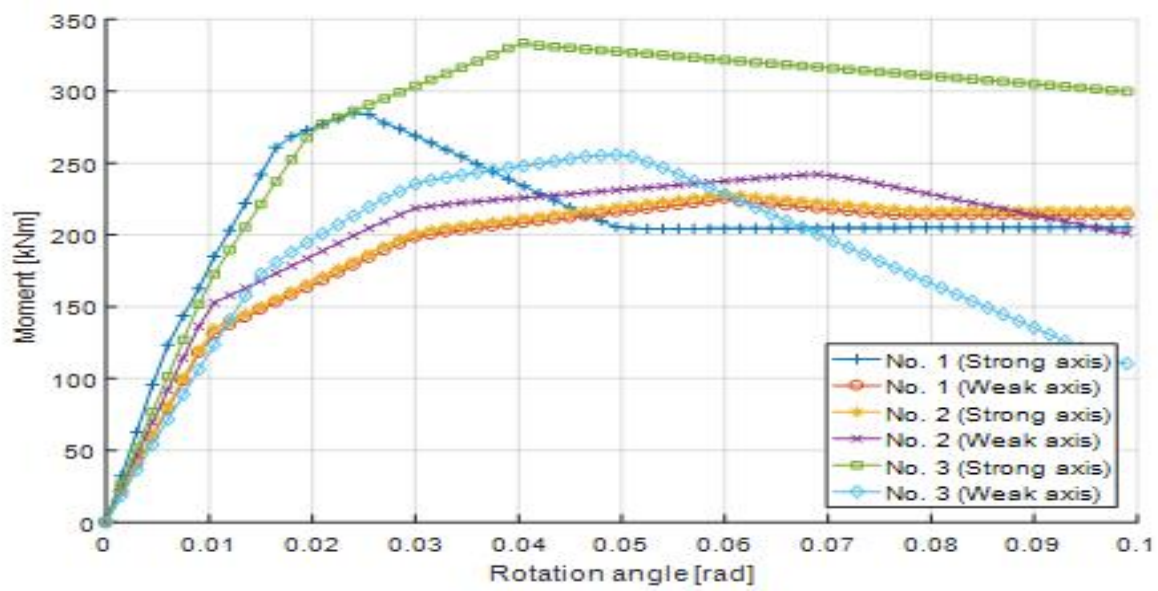

Fig. 3. Backbone curve for each connection configuration

\section{WIND LOADS}

ASCE 7 [14] defines two types of structural elements subjected to wind load: (1) main Wind-Force Resisting Systems (MWFRS), and (2) Components and Cladding (C\&C). A MWFRS is considered an assemblage of structural elements that work together to provide support and stability for the overall structure. C\&C elements are defined as elements of the building envelope that transfer the load to the main wind-force resisting system. Lateral wind pressure acting on the wall in this study were determined using the MWFRS since the focus was the connection of columns to base plate. The design wind pressures for the MWFRS of buildings can be determined by the following equation:

$$
\begin{gathered}
W=q G C_{p}-q_{h} G C_{p i} \\
q_{z}=0.613 K_{z} K_{z} t K_{d} V^{2}
\end{gathered}
$$

Where, $q_{z}=$ velocity pressure evaluated at height $\mathrm{z}, \mathrm{q}$ $=q_{z}$ for windward walls evaluated at height $\mathrm{z}$ of each floor elevation, $\mathrm{q}=q_{h}$ for leeward wall evaluated at mean roof height $\mathrm{h}, k_{z}=$ the velocity pressure exposure coefficient, $k_{z t}=$ the topographic factor, $q_{d}=$ the wind directionality factor, $\mathrm{V}=$ the basic wind speed (3-second gust wind speed at $10 \mathrm{~m}$ in open terrain) in $\mathrm{m} / \mathrm{s}, \mathrm{G}=$ gust-effect factor, $C_{p}$ = external pressure coefficient, and GCpi = internal pressure coefficient. $G C_{p i}$ was ignored since the geometry of structure is symmetric, thus the internal pressure has the same magnitude with opposing direction. Consequently, the wind pressure can be determined as following:

$$
W=0.613 K_{z} K_{z} t K_{d} V^{2} q G C_{p}
$$

Velocity pressure, q, depends on the projected walls, hence the total loads on building surface which the connec- tion need to withstand can be calculated as:

$$
R=W \times A=0.613 K_{z} K_{z} t K_{d} V^{2} G C_{p}\left(q_{z}-q_{h}\right) \times A
$$

where, $\mathrm{R}=$ base shear $(N)$, and A projected area $\left(m^{2}\right)$. Additionally, a commercial structural analysis software SAP 2000 was used to determine the load of most critical location amongst all connection. Afterward, the corresponding wind speed to generate this extent of load can be calculated as:

$$
V=\sqrt{\frac{R}{0.613 K_{z} K_{z} t K_{d} G C_{p}\left(q_{z}-q_{h}\right) \times A}}
$$

\section{LATERAL WIND FRAGILITY}

\section{A. Definition of Fragility Functions}

Fragility defined the relationship between the failure frequency of structure or their components and the intensity of disaster, i.e. wind speed. Fragility can be divided into empirical, analytical, and expert judgement fragility, which based on the method of their development. In general, fragility function can be defined as a mathematical function of probability whose variation generated by external excitation reached or exceeded a specified limit state. It is commonly described by lognormal distribution as following [16]:

$$
F r(x)=\Phi\left[\left(\ln (x)-{ }_{R}\right) / R\right]
$$

in which, $\Phi(\bullet)$ = standard normal cumulative distribution function, $\mu \mathrm{R}=$ logarithmic median of capacity $\mathrm{R}$ (in units that are dimensionally consistent with demand), and 
$\sigma \mathrm{R}=$ logarithmic standard deviation of capacity R. Fragilities can be used to identify a level of demand that a component or system will withstand with certain probability. Furthermore, the application of fragility curves can apply in both design and condition assessment applications [5].

\section{B. Fragility Analysis}

Analytical method by mean of MCS method was chose for the development of fragility in this study. Additionally, the limit state was rotation angle of the column. Four different damage states were used, they were the de- gree of rotation angle: $0.01 \mathrm{rad}$ (DS1), $0.02 \mathrm{rad}$ (DS2), 0.03 rad (DS4), and $0.04 \mathrm{rad}$ (DS4). These are the drift limits suggested by [17] and [18]. Moreover, in MCS method, statistical value of wind loads coefficient, which based on work by [4] and [6], was used. Correspondingly, summary of wind load statistics used in this study are shown in Table 2. From this value, a large set of simulated wind speed could be determined with Eq. 5. Therefore, parameters $\mu \mathrm{R}$ and $\sigma \mathrm{R}$ of wind fragility can be determined, since it follows lognormal CDF as shown in Eq. 6. In this simulation, each parameter was assumed independent.

TABLE 2

Summary of wind load parameters statistics

\begin{tabular}{lllllll}
\hline \hline Parameter & Category & Mean-to-Nominal & COV & Nominal & Mean & SD \\
\hline \multirow{4}{*}{$K_{z}$} & Exposure B & 1.01 & 0.19 & 0.72 & 0.73 & 0.14 \\
& Exposure C & 0.96 & 0.14 & 1.00 & 0.96 & 0.13 \\
$K_{d}$ & Exposure D & 0.97 & 0.14 & 1.18 & 1.14 & 0.16 \\
$K_{z t}$ & MWFRS & & & deterministic (1.0) & & \\
& & & deterministic (1.0) & & & \\
$\mathrm{G}$ & Exposure B & 0.96 & 0.12 & 0.80 & 0.77 & 0.09 \\
& Exposure C & 0.98 & 0.12 & 0.85 & 0.83 & 0.10 \\
$C_{p}$ & Exposure D & 0.98 & 0.08 & 0.85 & 0.83 & 0.07 \\
& Windward & 0.88 & 0.14 & 0.8 & 0.70 & 0.1 \\
& Leeward & 0.94 & 0.15 & -0.5 & -0.47 & 0.07 \\
\hline \hline
\end{tabular}

\section{RESULTS AND DISCUSSIONS}

Fragility curves of building subjected to lateral wind load were shown for different damage states (DS), connection types and their loading directions, exposure conditions, and wind directions.

Parameters $\mu_{R}$ and $\sigma_{R}$ of wind fragility was estimated with Maximum Likelihood Method (MLE) [17]. These parameters were included in the figures for ease of comparison.

\section{A. Fragility for Each Damage States}

Fragility curves for Type 3 connection with loading on strong axis (perpendicular to the web of I-beam) and exposure condition $\mathrm{B}$, which was common in urban area, was shown in Fig. 4.

The wind direction was perpendicular to the length of building. DS1 is further away from the other three damage states, this was expected due to the resistance capacity in Fig. 3.

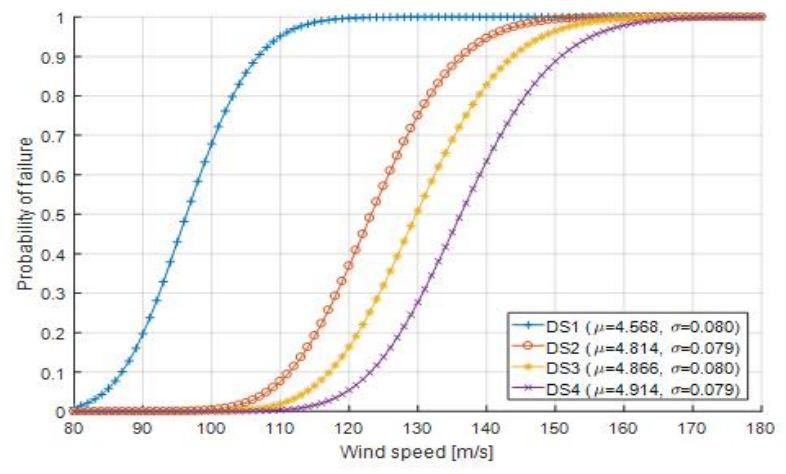

Fig. 4 . Fragility curve for type 3 (strong axis) in wind exposure B and wind direction perpendicular to length of building

\section{B. Fragility for Different Connection Types}

In Fig. 5, fragility curves for all types of connection was shown. The leftmost curve, which belong to connection Type 3 (weak axis loading), was the most vulnerable. This 
curve had logarithmic median of capacity $\mu=4.394$ and logarithmic standard deviation of capacity $\sigma=0.081$. It means that median of failure probability and standard deviation of building with connection Type 3 was $81 \mathrm{~m} / \mathrm{s}$ and 0.081 , respectively. Compare that to the less vulnerable curve on the rightmost which had median of failure probability 100 $\mathrm{m} / \mathrm{s}$. This result could be used to quantify the risk of different types of connection.

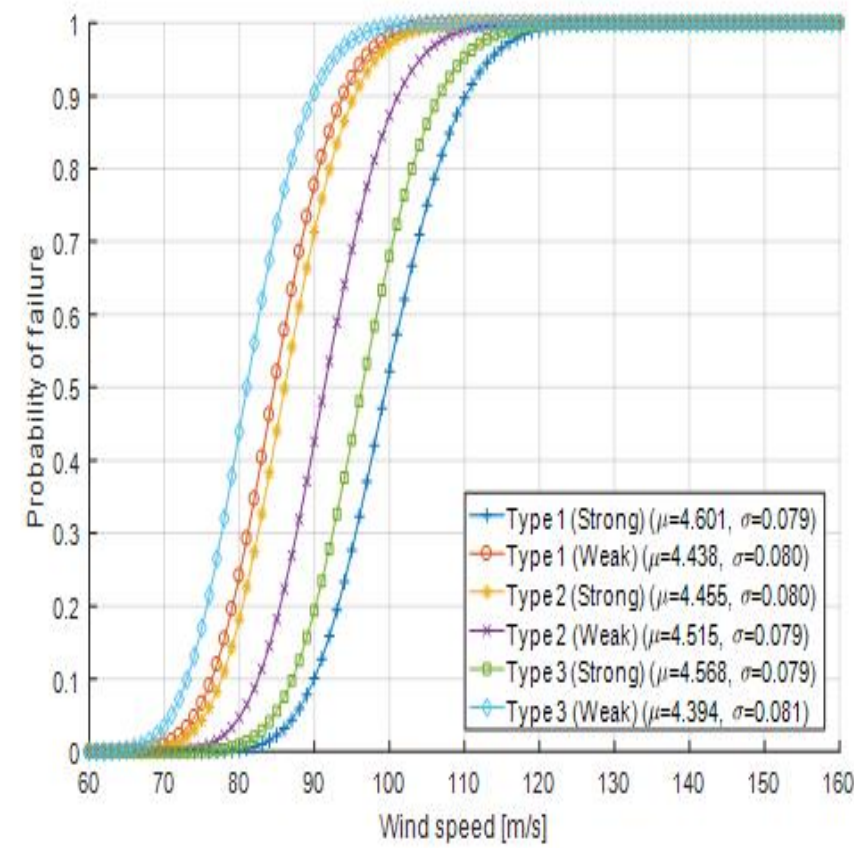

Fig. 5. Fragility curve for all types of connection in DS1 with wind exposure $\mathrm{B}$ and wind direction perpendicular to length of building

\section{Fragility for Different Exposure Condition and Wind Direction}

Fig. 6 shows that in urban area exposure B (the rightmost blue curve) was the less susceptible to failure due to high wind, which has the probability of failure $50 \%$ occur at wind speed $100 \mathrm{~m} / \mathrm{s}$. This is expected since exposure B is situated at an urban area with other structure to reduce the wind loads coefficient [14].

Furthermore, the effect of wind direction on building was also shown in Fig. 7. The directions considered were perpendicular and parallel to the long dimension of building. When the projected area was large, the magnitude of wind loads was higher [14], which resulted in higher probability as can be seen in blue curve on the leftmost of Fig. 7 .

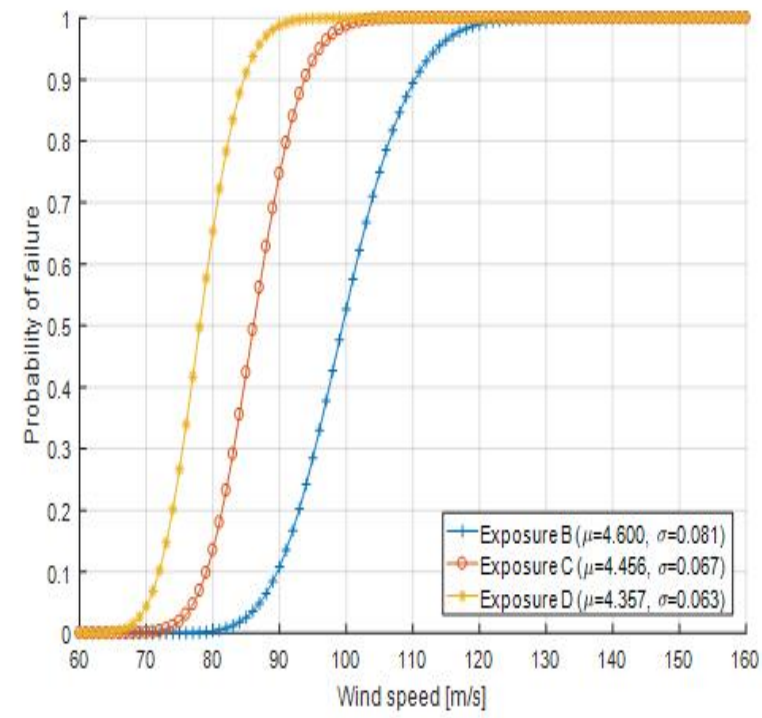

Fig. 6. Fragility curve for different wind exposure category of connection Types 2 (strong axis) in DS1

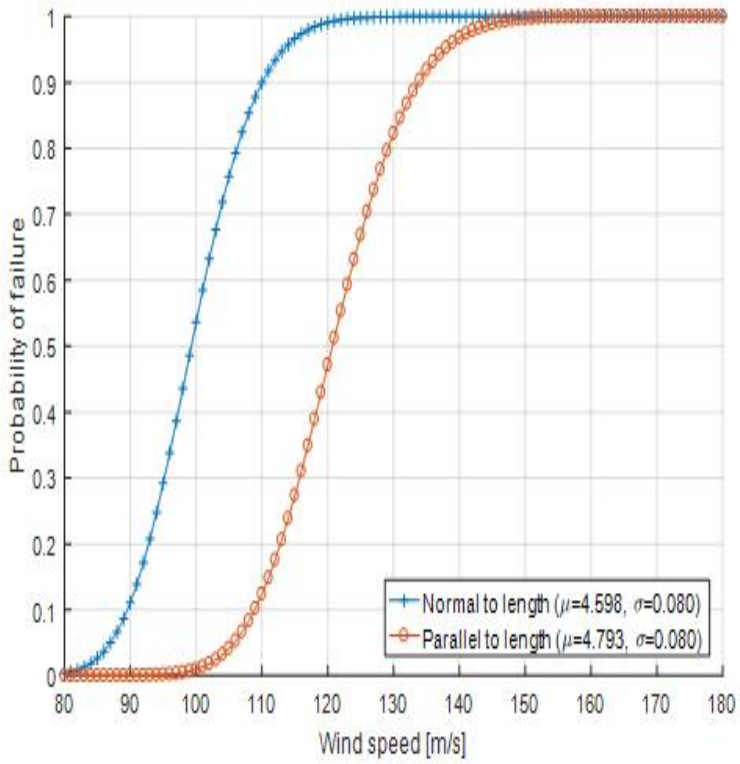

Fig. 7. Fragility curve for different wind direction in exposure $B$ of connection Types 2 (strong axis) in DS1

\section{CONCLUSIONS}

Fragility curve for different types of connection in lightweight steel frame structure subjected to lateral wind loads was determined in this study. Furthermore, parameters affecting the wind load was also considered such as exposure category and wind direction. By mean of Monte Carlo Simulation, large number of wind speed that result 
in damage of building per the defined limit state was obtained. Afterward, maximum likelihood estimation method was employ to determine the parameters $\mu$ and $\sigma$ of fragility, which follow the cumulative lognormal distribution function.

Results show that wind direction parallel to long dimension of structure was the most critical condition as can be seen the average difference in probability of failure was about $40 \%$. Furthermore, depend on type of connection, the failure probability of building could greatly increase, for example, between Type 1 and Type 3 connection. Moreover, from DS1 to DS2 there was a large gap, this is due to the disengagement of anchor rod during experiment. Additionally, the median probability of failure occurs at a very high wind speed, which mean that the failure for this type of building subjected to wind loads would be infrequent. However, further study with detail structural analysis could narrow down the uncertainty in this study.

In conclusion, usage of this methodology could lead to a more predictable structure performance and facilitate the introduction of performance-base design guidelines. Fragilities such as those presented here also can convolved with wind hazard curves to develop a risk assessment tool, which can evaluate the potential impact of a natural hazard in public planning and mitigate the consequent economic losses and social disruption.

\section{ACKNOWLEDGMENT}

This research was supported by a grant (MPSS-NH2015-79) from Disaster Prediction and Mitigation Technology Development Program funded by Korean Ministry of Public Safety and Security (MPSS).

\section{REFERENCES}

[1] S. J. Chen, C. H. Yeh and J. M. Chu, "Ductile steel beam-to-column connections for seismic resistance," Journal of Structural Engineering, vol. 122, no. 11, pp. 1292-1299, 1996. DOI: 10.1061/(ASCE)0733-9445(1996)122:11(1292)

[2] L. T. D. Ha and K. M. T. Tsai, -Numerical study on optimization of wooden-steel hybrid beams base on shape factor of steel component,\| International Journal of Technology and Engineering Studies, Vol. 1, no. 2, pp. 53-62, 2015.

[3] National Typhoon Center, Typhoon White Book. Jeju, South Korea: The Korean Meteorological Administration, 2011.
[4] K. H. Lee and D. V. Rosowsky, "Fragility curves for woodframe structures subjected to lateral wind loads," Wind and Structures, vol. 9, no. 3, pp. 217-230, 2006. DOI: 10.12989/was.2006.9.3.217

[5] B. R. Ellingwood, D. V. Rosowsky, Y. Li and J. H. Kim, "Fragility assessment of light-frame wood construction subjected to wind and earthquake hazards," Journal of Structural Engineering, vol. 130, no. 12, pp. 1921-1930, 2004 . DOI: 10.1061/(ASCE)0733-9445(2004)130:12(1921)

[6] B. R. Ellingwood and P. B. Tekie, "Wind load statistics for probability-based structural design," Journal of Structural Engineering, vol. 125, no. 4, pp. 453-463, 1999. DOI: 10.1061/(ASCE)0733-9445(1999)125:4(453)

[7] American Society of Civil Engineers, Minimum Design Loads for Buildings and Other Structures, vol. 7. Virginia, VA: American Society of Civil Engineers.

[8] A. D. Cope,"Predicting the vulnerability of typical residential buildings to hurricane damage," Doctoral dissertation, University of Florida, Florida, FL, 2004.

[9] H. Ham, S. Lee and H. Kim, "Development of typhoon fragility for industrial buildings," in Proceeding of the 7th Asia-Pacific Conference on Wind Engineering, Taipei, Taiwan, 2009.

[10] S. S. Lee, H. S. Kim, Y. K. Lee and K. C. Shim, "Risk assessment of strong wind over industrial facilities in Shipyards," Journal of Korean Society of Hazard Mitigation, vol. 9, no. 4, pp. 21-28, 2009.

[11] N. Semsri, C. Torasa, K. Samerjai, M. Suksombat and P. Sinpeng, "Electricity-generating wind turbine from electric bicycle motor," International Journal of Technology and Engineering Studies, vol. 2, no. 4, pp. 101-109, 2016.

[12] Z. Huang, D. V. Rosowsky and P. R. Sparks, "Long-term hurricane risk assessment and expected damage to residential structures," Reliability Engineering \& System Safety, vol. 74, no. 3, pp. 239-249, 2001.

DOI: $10.1016 /$ S0951-8320(01)00086-2

[13] A. H. Ang and W. H. Tang, "Probability Concepts in Engineering Planning and Design: Decision, Risk, and Reliability, vol. 2. New York, NY: John Wiley \& Sons Inc, 1984.

[14] American Institute of Steel Construction, Seismic Provisions for Structural Steel Buildings. Chicago, IL: American Institute of Steel Construction, 2010.

[15] B. F. Maison and M. S. Speicher, "Loading Protocols for ASCE 41 Backbone Curves," Earthquake Spectra, vol. 32, no. 4, pp. 2513-2532, 2016. DOI: 10.1193/010816EQS007EP 
[16] K. Porter, "Beginner's guide to fragility, vulnerability, and risk. Encyclopedia of Earthquake Engineering, 235-260, 2015.

[17] FEMA, "Prestandard and commentary for the seismic rehabilitation of buildings," Report FEMA-356, Federal Emergency Management Agency, Washington, DC., WA, 2000 .
[18] FEMA, "Commentary for the seismic rehabilitation of buildings," Report FEMA-356, Federal Emergency Management Agency, Washington, DC., WA, 2000.

[19] M. Shinozuka, M. Q. Feng, J. Lee and T. Naganuma, "Statistical analysis of fragility curves," Journal of Engineering Mechanics, vol. 126, no. 12, pp. 1224-1231, 2000. DOI: $10.1061 /(A S C E) 0733-9399(2000) 126: 12(1224)$

— This article does not have any appendix. — 